\title{
Analisis Pola Pertumbuhan Arsitektur Bisnis Sekolah Berdasarkan CMM
}

\author{
Widya Wahyu Pratiwi, M. Faiz Fathoni, Arif Santoso, M. Ainul Yaqin \\ Jurusan Teknik Informatika, Fakultas Sains dan Teknologi \\ UIN Maulana Malik Ibrahim Malang \\ Jl. Gajayana No. 50,Malang 65144, Indonesia \\ widyawahyu019@gmail.com,mfaizf96@gmail.com,ariief78@gmail.com, yaqinov@ti.uin- \\ malang.ac.id
}

\begin{abstract}
School is an educational institution established by the government / private sector with ageappropriate levels. Every school has a business process, such as the admission process for new students, the teaching and learning process by students and teachers, the process of supporting facilities for educational processes, is the pattern of every set of business process architecture in the school. Each school needs standardization which is continuously improved to match the national school standard (SSN) that has been set by the government in Government Regulation No. 19 of 2005. Good school standardization can be seen from the growing patterns of business architecture with high complexity, in mark the number of students, integrated teaching curriculum, and complete infrastructure to support school activities. So in this study, conducting an analysis of the growth patterns of business architecture in schools in order to facilitate decision making and as a reference in the education process so that schools can be well standardized, by measuring the level of maturity of the capabilities of processes in the architectural pattern of school business processes using Capability Maturity Model (CMM), the result of this study is an analysis of the growth patterns of school business architecture with the maturity of business process patterns in accordance with national school standards, which can provide information as a support in business process activities in schools
\end{abstract}

Keywords: Business Architecture, Growth Pattern, Capability Maturity Model

\begin{abstract}
Abstrak
Sekolah merupakan suatu lembaga pendidikan yang didirikan oleh pemeritah/swata dengan tingkatan-tingkatan sesuai umur. Setiap sekolah memiliki proses bisnis, seperti proses penerimaan siswa/siswi baru, proses belajar mengajar oleh siswa dan guru, proses perlengkapan sarana prasana pendukung proses pendidikan, merupakan pola dari setiap rangkaian arsitektur proses bisnis yang ada di sekolah. Tiap-tiap sekolah memerlukan standarisasi yang terus di tingkatkan agar sesuai dengan standart sekolah nasional (SSN) yang telah di tetapkan pemerintah dalam Peraturan Pemerintah No 19 Tahun 2005. Standarisasi sekolah yang baik dapat di lihat dari pola tertumbuhan arsitektur bisnis dengan kompleksitas yang tinggi, di tandai dengan banyaknya siswa/siswi,kurikulum pengajaran yang terintegritas, serta lengkapnya sarana prasarana sebagai pendukung kegiatan sekolah. Maka pada penelitian ini, melakukan suatu analisis terhadap pola pertumbuhan arsitektur bisnis yang ada di sekolah guna mempermudah dalam mengambil keputusan serta sebagai acuan dalam proses pendidikan sehingga sekolah dapat terstandarisasi dengan baik, dengan mengukur tingkat kematangan kapabilitas prosesproses dalam pola arsitektur proses bisnis sekolah menggunakan Capability Maturity Model (CMM), hasil dari penelitian ini adalah analisis pola pertumbuhan arsitektur bisnis sekolah dengan kematangan pola proses bisnis sesuai dengan standart sekolah nasional, yang dapat memberikan informasi sebagai penunjang dalam kegiatan proses bisnis yang ada di sekolah.
\end{abstract}

Kata kunci: Arsitektur Bisnis, Pola Pertumbuhan, Capability Maturity Model 


\section{PENDAHULUAN}

Sekolah merupakan lembaga struktural yang membutuhkan pertumbuhan secara terus menerus setiap waktu, pola proses bisnis dalam sekolah pun terus bertumbuh dari pola proses bisnis sederhana menjadi pola proses bisnis yang kompleks, sesuai dengan Standart Sekolah Nasional (SSN), maka dari itu arsitektur proses bisnis berperan penting untuk membantu sekolah menangani berbagai persoalan, sebagai acuan dalam mengambil keputusan yang tepat sehingga sekolah memiliki standarisasi untuk bertumbuh dan bersaing secara lebih efektif, yang tingkat kematangan dari setiap pola pertumbuhannya berpatokan pada Capability Maturity Model (CMM). Pada Capability Maturity Model (CMM) pola pertumbuhannya di golongakan menjadi 5 bagian level, yang nantinya 5 level tersebut yan menjadi tolak ukur dari sekolah yang sesuai dengan Standart Nasional Pendidikan (NSP) yang di tetapkan pemerintah. Hasil akhir dari penilitian ini adalah graf-graf yang menjadi acuan dari pola pertumbuhan proses bisnis di dalam lembaga pendidikan yang efektif.

\section{METODOLOGI PENELITIAN}

\subsection{Sub bab 1 Data Penelitian}

Pada penelitian ini menggunakan acuan data ang telah di tetapkan dalam Undang-Undang Nomor 19 tahun 2015 Tentang Standar Sekolah Nasional

\subsection{Sub bab 2 Intrumen Pengumpulan Data a. Data Primer}

Data primer pada penelitian ini merupakan data yang diperoleh secara langsung dari sumbernya. Seperti : melakukan wawancara tehadap sekolah, menanyakan jumlah kelas, jumlas siswa-siswi, jumlah guru serta sarana prasarana

\section{b. Data Sekunder}

Penelitian menggunakan pendekatan data-data yang telah ada, selanjutnya dilakukan proses analisa dan interpretasi terhadap data-data tersebut sesuai dengan tujuan penelitian. Seperti: data Aset yang ada di sekolah, Kerjasama yang dilakukan sekolah, Data struktur sekolah Pada pelitian ini menggunakan pengulan data sekunder, dan litelatur lain sebagai pendukung penelitian ini

\subsection{Sub bab 3 Prosedur Penelitian}

Menggunakan penelitian kualitatif, dalam dunia pendidikan penelitian kualitatif mempunyai tujuan menggambarkan proses kegiatan pendidikan berdasarkan pada apa yang ada di lapangan sebagai bahan kajian untuk menemukan kekurangan dan kelemahannya sehingga bisa ditentukan upaya untuk memperbaikinya, menganalisis suatu gejala, fakta, dan peristiwa pendidikan yang ada di lapangan.

\subsection{Sub bab 4 Strandar Sekolah Nasional}

Sekolah yang telah memenuhi Standar Nasional Pendidikan (SNP) yang berarti memenuhi tuntutan SPM sehingga diharapkan mampu memberikan layanan pendidikan yang standar dan menghasilkan lulusan dengan kompenetensi 
sesuai dengan standar nasional yang ditetapkan. Berdasarkan Undang Undang Nomor 19 Tahun 2015 Tentang Strandar Sekolah Nasional, secara garis besarnya terdapat beberapa komponen indikator :

a) Memiliki tenaga kependidikan yang cukup jumlahnya,

b) Kualifikasi dan kompetensi yang memadadi sesuai dengan tingkat pendidikan yang ditugaskan,

c) Tidak mismatched. Berkaitan dengan aspek kesiswaan, ada enam hal yang harus diperhatikan sekolah: penerimaan siswa baru, penyiapan belajar peserta didik, pembinaan dan pengembangan, pembimbingan, pemberian kesempatan, dan evaluasi hasil beljar siswa.

\subsection{Arsitektur Bisnis}

Secara umum arsitektur bisnis menggambarkan kumpulan aktivitas bisnis, data dan informasi yang ada dalam lingkungan internal dan eksternal organisasi. Arsitektur bisnis adalah representasi formal dan tools serta informasi bagi profesional bisnis organisasi dalam menilai, merubah, dan merancang bisnis (SOA, 2010).

\subsection{Capability Maturity Model (CMM)}

CMM adalah model kematangan kemampuan untuk membantu pendefinisian dan pemahaman proses-proses pada suatu organisasi. Nilai yang diukur di Capability Maturity Model yaitu :

a) Apa yang diukur (Parameter)

b) Bagaimana cara mengukurnya (Metode)

c) Bagaimana standar penilaiannya (Skala Penilaian)

d) Bagaimana Interpretasinya (Bagi Manusia)

Mengacu pada definisi CMM tersebut maka kita dapat mengetahui CMM sebagai alat bantu untuk menilai keunggulan kompetitif yang dimiliki sebuah perusahaan. Menurut Dennis M. Ahern, Aaron Clouse dan Richard Turner CMM adalah adalah suatu pendekatan yang berfungsi untuk meningkatkan proses piranti lunak (software process) di dalam organisasi agar menjadi lebih efisien dan efektif, Setidaknya ada lima level kematangan dalam implementasi CMM pada bisnis sekolah, antara lain:

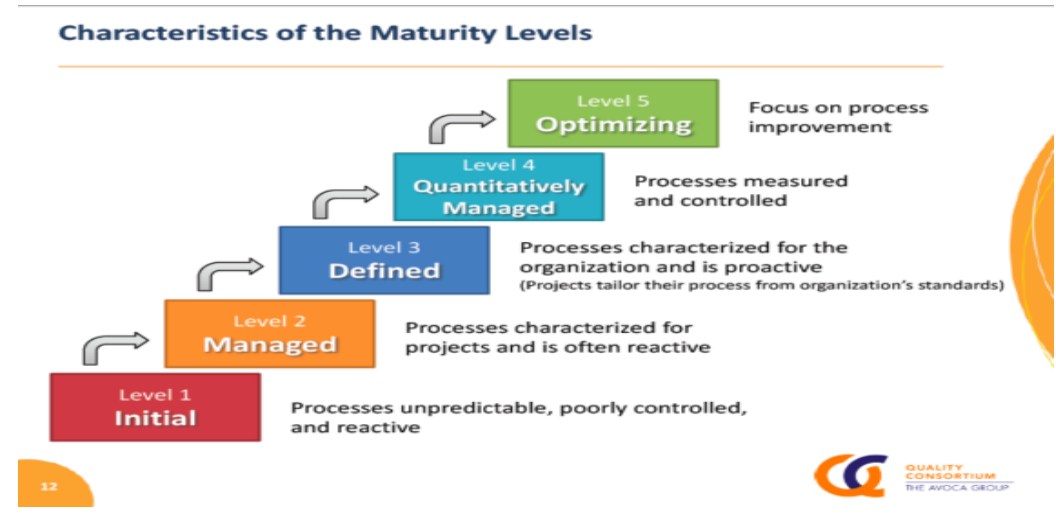

Gambar 1. Level dalam CMM 
Jurnal Riset Sistem Informasi Dan Teknik Informatika (JURASIK)

Volume 5 Nomor 1 Februari, pp 102-108

ISSN: 2527-5771/EISSN: 2549-7839

http://tunasbangsa.ac.id/ejurnal/index.php/jurasik

\begin{tabular}{|c|c|c|c|}
\hline Level & Focus & Process Areas & Result \\
\hline$\stackrel{5}{\text { Optimizing }}$ & $\begin{array}{l}\text { Continuous } \\
\text { process } \\
\text { improvement }\end{array}$ & $\begin{array}{l}\text { Organizational Innovation \& } \\
\text { Deployment } \\
\text { Causal Analysis and Resolution }\end{array}$ & \multirow[t]{4}{*}{$\begin{array}{l}\text { Productivity } \\
\& \text { Quality }\end{array}$} \\
\hline $\begin{array}{l}4 \\
\text { Quantitatively } \\
\text { Managed }\end{array}$ & $\begin{array}{l}\text { Quantitative } \\
\text { management }\end{array}$ & $\begin{array}{l}\text { Organizational Process Performance } \\
\text { Quantitative Project Management }\end{array}$ & \\
\hline $\begin{array}{c}3 \\
\text { Defined }\end{array}$ & $\begin{array}{l}\text { Process } \\
\text { standardization }\end{array}$ & $\begin{array}{l}\text { Requirements Development } \\
\text { Technical Solution } \\
\text { Product Integration } \\
\text { Verification } \\
\text { Validation } \\
\text { Organizational Process Focus } \\
\text { Organizational Process Definition } \\
\text { Organizational Training } \\
\text { Integrated Project Management } \\
\text { Risk Management } \\
\text { Decision Analysis and Resolution }\end{array}$ & \\
\hline$\stackrel{2}{2}$ & $\begin{array}{l}\text { Basic project } \\
\text { management }\end{array}$ & $\begin{array}{l}\text { Requirements Management } \\
\text { Project Planning } \\
\text { Project Monitoring \& Control } \\
\text { Supplier Agreement Management } \\
\text { Measurement and Analysis } \\
\text { Process \& Product Quality Assurance } \\
\text { Configuration Management }\end{array}$ & \\
\hline $\begin{array}{c}1 \\
\text { Initial }\end{array}$ & \multicolumn{2}{|c|}{ Competent people and heroics } & \\
\hline
\end{tabular}

Gambar 2. Rician level dalam CMM

\section{HASIL DAN PEMBAHASAN}

Berdasarkan Standar Sekolah Nasional (SSN) yang telah di tetapkan pemerintah, yang telah diatur dalang Undang-Undang no 19 Tahun 2015, digunakan sebagai acuan gambaran pola dalam proses bisnis yang ada di sekolah, salah satu elemen penting sebagai tolak ukur perkembangan pola pertumbuhan proses bisnis adalah meningkatnya jumlah siswa dan di cukupinya sarana prasarana . berikut adalah arsitektur bisnis yang di terapkan dalam Capability Maturity Model (CMM) :

Tabel 1. Tabel level 1 sampai 5 dalam Capability Maturity Model (CMM)

\begin{tabular}{|c|c|c|}
\hline Maturnity level & focus & Process areas \\
\hline $\begin{array}{l}\text { Level } 1 \\
\text { Initial }\end{array}$ & $\begin{array}{l}\text { Orang / oknum / pelaku } \\
\text { bisnis (seluruh yang } \\
\text { berada dalam sekolah) }\end{array}$ & $\begin{array}{l}\text { Orang orang kompeten yang } \\
\text { melaksanakan kewajibannya }\end{array}$ \\
\hline $\begin{array}{c}\text { Level } 2 \\
\text { managed }\end{array}$ & $\begin{array}{c}\text { Proses project } \\
\text { menejemen dalam bisnis } \\
\text { sekolah }\end{array}$ & $\begin{array}{l}\text { 1. Jaminan kualitas project } \\
\text { belajar mengajar dalam } \\
\text { sekolah } \\
\text { 2. Pengecekan dan pengawasan } \\
\text { pada sistem belajar }\end{array}$ \\
\hline $\begin{array}{l}\text { Level } 3 \\
\text { defined }\end{array}$ & $\begin{array}{c}\text { Proses belajar mengajar } \\
\text { guru dan kinerja tata } \\
\text { usaha }\end{array}$ & $\begin{array}{ll}\text { 1. } & \text { Kinerja } \\
\text { 2. Koordinasi rekan } \\
\text { 3. Program pelatihan } \\
\text { 4. Proses organisasi }\end{array}$ \\
\hline $\begin{array}{c}\text { Level } 4 \\
\text { Quantitatively } \\
\text { managed }\end{array}$ & $\begin{array}{l}\text { Hasil dan kualitias segala } \\
\text { proses }\end{array}$ & Manajemen proses kualitatif \\
\hline $\begin{array}{c}\text { Level } 5 \\
\text { Optimizing }\end{array}$ & $\begin{array}{l}\text { Melanjutkan proses dan } \\
\text { memperbaiki }\end{array}$ & $\begin{array}{l}\text { 1. Penjegahan kerusakan sistem } \\
\text { 2. Memenejemen perubahan } \\
\text { teknologi } \\
\text { 3. Memenejemen proses yang } \\
\text { telah diubah }\end{array}$ \\
\hline
\end{tabular}


Dari table level 1-5 Capability Maturity Model (CMM) dapat di lihat proses bisnis secara garis besar, maka dari itu dilakukan pendetailan pada setiap unsur pokoknya, di hasil sebagai berikut :

Tabel 2. Detail Tabel level 1 sampai 5 dalam Capability Maturity Model (CMM)

\begin{tabular}{|c|c|c|}
\hline $\begin{array}{c}\text { Maturnity } \\
\text { Level }\end{array}$ & Focus & Kategori \\
\hline $\begin{array}{l}\text { Level } 1 \\
\text { Initial }\end{array}$ & $\begin{array}{l}\text { Orang / } \\
\text { oknum / } \\
\text { pelaku bisnis } \\
\text { (seluruh } \\
\text { yang berada } \\
\text { dalam } \\
\text { sekolah) }\end{array}$ & $\begin{array}{l}\text { Bisnis sekolah } \\
\text { Terdiri dari beberapa guru dan membuka beberapa } \\
\text { program kelas } \\
\text { - } 1 \text { guru untuk } 20 \text { siswa siswi dalam } 1 \text { kelas }\end{array}$ \\
\hline $\begin{array}{l}\text { Level } 2 \\
\text { managed }\end{array}$ & $\begin{array}{l}\text { Project } \\
\text { manager }\end{array}$ & $\begin{array}{l}\text { 10 knowledge area: } \\
\text { 1. manajemen cakupan, pendefinisian elemen yang } \\
\text { melakukan proses bisnis. } \\
\text { Ex: } 1 \text { wali kelas menangani } 1 \text { kelas berisi } 30 \text { siswa. } \\
\text { manajemen waktu, mengestimasi durasi yang } \\
\text { diperlukan untuk menyelesaikan pekerjaan. } \\
\text { Ex: pembuatan jadwal mengajar setiap guru dalam } \\
\text { satu minggu dan pembuatan jadwal belajar setiap } \\
\text { kelas untuk satu minggu. } \\
\text { manajemen biaya, berkaitan dengan budget dalam } \\
\text { pengembangan infrastuktur, fasilitas dalam sekolah. } \\
\text { Ex : pengelolaan dana yang diterima oleh sekolah } \\
\text { untung pengembangan sarana prasarana. } \\
\text { manajemen kualitas, setiap proses bisnis memenuhi } \\
\text { kebutuhan murid maupun tenaga pengajar. } \\
\text { Ex : Penetapan guru setiap mata pelajaran agar } \\
\text { proses pembelajaran menjadi lebih baik. } \\
\text { manajemen sumberdaya manusia setiap pelaku } \\
\text { bisnis dalam sekolah. } \\
\text { Ex : porsi mengajar sesuai dengan kapasitas dan } \\
\text { bidang. } \\
\text { manajemen komunikasi, setiap pembuatan, } \\
\text { pengumpulan, penyebaran, dan penyimpanan } \\
\text { informasi tentang proses bisnis dalam sekolah. } \\
\text { Ex : pembuatan media informasi oleh tenaga } \\
\text { pengajar guna menyebaran informasi pada setiap } \\
\text { elemen pelaku bisnis. } \\
\text { manajemen resiko, pelaku bisnis yang } \\
\text { mengidentifikasi, menganalisa, dan merespon } \\
\text { terhadap berbagai jenis resiko. } \\
\text { Ex : penambahan salah seorang tenaga pengajar } \\
\text { sebagai tenaga konseling untuk siswa. } \\
\text { manajemen pengadaan, pelaku bisnis yang } \\
\text { bertangung jawab memberikan barang atau } \\
\text { mayanan kepada murid. } \\
\text { Ex : penambahan staf sarana prasarana untuk } \\
\text { 6. }\end{array}$ \\
\hline
\end{tabular}


Jurnal Riset Sistem Informasi Dan Teknik Informatika (JURASIK)

Volume 5 Nomor 1 Februari, pp 102-108

ISSN: 2527-5771/EISSN: 2549-7839

http://tunasbangsa.ac.id/ejurnal/index.php/jurasik

\begin{tabular}{|c|c|c|}
\hline $\begin{array}{c}\text { Maturnity } \\
\text { Level }\end{array}$ & Focus & Kategori \\
\hline & & $\begin{array}{l}\text { Ex : Pelaku bisnis seperti kepala sekolah mengelola } \\
\text { dan mengontrol selama berjalannya proses bisnis } \\
\text { 10. manajemen integrasi, dimana pelaku bisnis yang } \\
\text { dapat berpengaruh dan mempengaruhi keutuhan } \\
\text { seluruh elemen sekolah } \\
\text { Ex : tugas kepala kepala sekolah sebagai } \\
\text { penanggung jawab. }\end{array}$ \\
\hline $\begin{array}{l}\text { Level } 3 \\
\text { defined }\end{array}$ & $\begin{array}{l}\text { Proses } \\
\text { belajar } \\
\text { mengajar } \\
\text { guru dan } \\
\text { kinerja tata } \\
\text { usaha sesuai } \\
\text { dengan } \\
\text { Standart } \\
\text { Sekolah } \\
\text { Nasional } \\
\text { (SSN) }\end{array}$ & 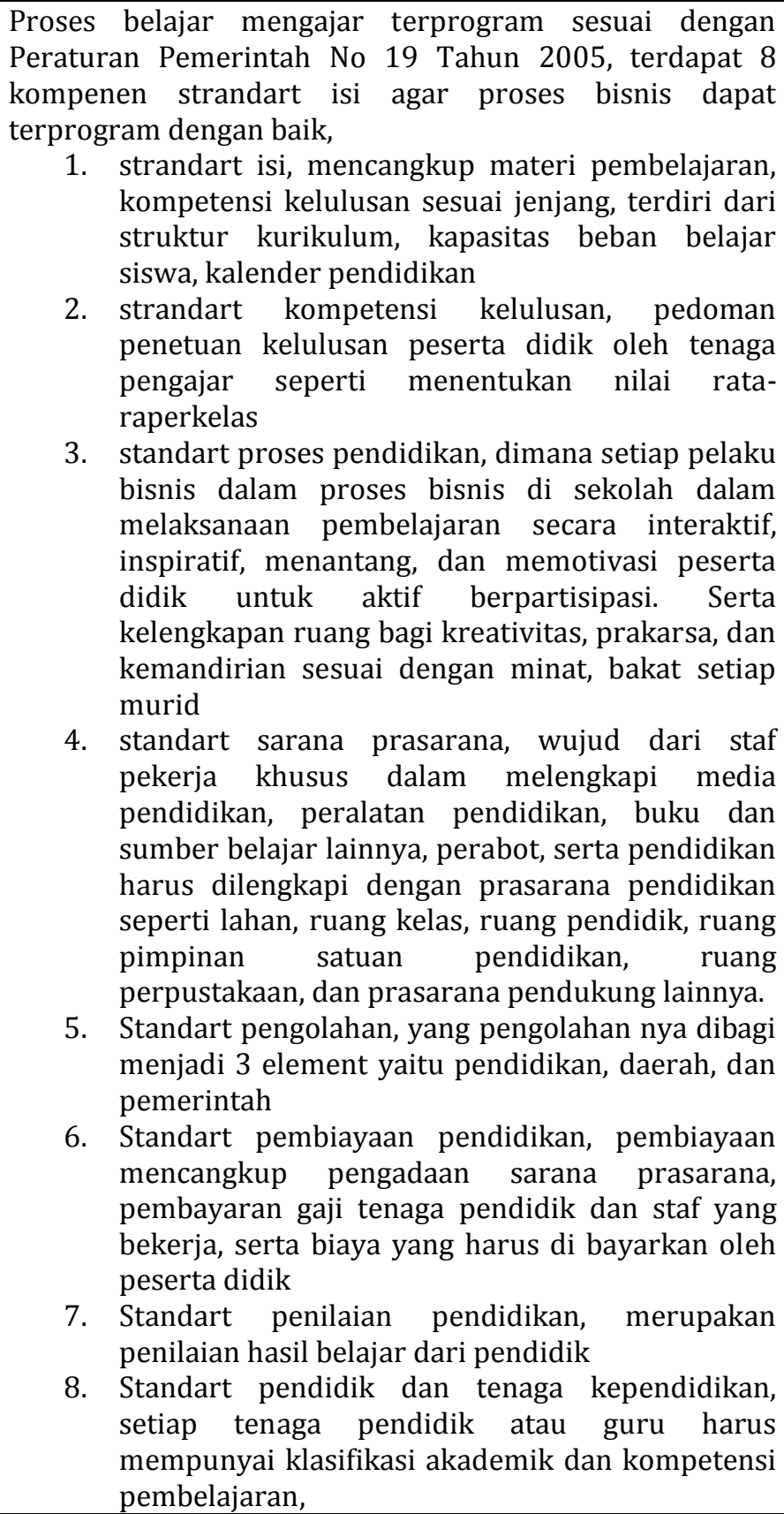 \\
\hline $\begin{array}{l}\text { Level } 4 \\
\text { Quantitatively } \\
\text { managed }\end{array}$ & $\begin{array}{l}\text { Pengukuran } \\
\text { kinerja }\end{array}$ & $\begin{array}{l}\text { Dari kurikulum pendidikan yang di buat oleh tenaga } \\
\text { pendidik, menghasilkan sistem belajar mengajar yang } \\
\text { terintegrasi dengan baik sehingga membentuk murid }\end{array}$ \\
\hline
\end{tabular}


Jurnal Riset Sistem Informasi Dan Teknik Informatika (JURASIK)

Volume 5 Nomor 1 Februari, pp 102-108

ISSN: 2527-5771/EISSN: 2549-7839

http://tunasbangsa.ac.id/ejurnal/index.php/jurasik

\begin{tabular}{|c|c|c|}
\hline Maturnity & Focus & Kategori \\
\hline & & $\begin{array}{l}\text { dengan kemampuan akdemik dan non akademik yang } \\
\text { baik. } \\
\text { Serta terwujudnyan pengadaan baik penambahan fasilitas } \\
\text { ruangan dan pengurus sebagai tempat ekstrakulikuler } \\
\text { akademik dan non akademik seperti perpustakaan dan } \\
\text { gedung olah raga }\end{array}$ \\
\hline $\begin{array}{l}\text { Level } 5 \\
\text { Optimizing }\end{array}$ & Optimasi & $\begin{array}{l}\text { Dengan ada kepala sekolah, guru yang mengajar, petugas } \\
\text { tata usaha dan petugas pengembangan fasilitas } \\
\text { kemampuan siswa dan siswi, maka perlu diadakannya } \\
\text { 1. Pelatihan kepala sekolah } \\
\text { 2. Pengembangan silabus dan kurikulum pengajaran } \\
\text { 3. Pelengkapan dan penambahan kualitas buku di } \\
\text { perpus serta kelengkapan perlatan ekstrakurikuler } \\
\text { Sebagai bentuk dalam pengoptimalan proses bisnis }\end{array}$ \\
\hline
\end{tabular}

\section{SIMPULAN}

Sesuai dengan tujuan penelitian ini dimana, diharapkan dengan penerapan metode CMM dapat dikatakan membawa perubahan baik kepada sekolah, sehingga sekolah dapat menjalankan proses bisnis sesuai dengan ketetapan pemerintah. Dengan adanya hasil seperti ini dalam pengembangan berikutnya sekolah menjadi lebih optimal dalam melaksanakan proses bisnis.

\section{DAFTAR PUSTAKA}

[1] Penelitian, B. Standar Nasional, and C. Standar Nasional Pengabdian Masyarakat. "Standar Nasional Pendidikan Tinggi." (2014)..

[2] Indonesia, PRESIDEN REPUBLIK. Peraturan Pemerintah Republik Indonesia nomor 19 tahun 2005 tentang standar nasional pendidikan. Departemen Pendidikan Nasional Republik Indonesia, 2005.

[3] Lee, D.Y., Won, S.K., Han, C.H., Cho, M.Y., and Lee, J.B. "Application of Configuration Management for Engineering Information Management in Pipeline Projects". 34th International Symposium on Automation and Robotics in Construction, 2017.

[4] Estublier, J. "Software Configuration Management : A Roadmap". Dassault Systèmes / LSR, Grenoble University Bat C, BP 5338041 Grenoble 9 France, 2000.

[5] Aguiar, J.G., Kinchin, I.M., Heron M., Correi, P.R.M. "Comparing Interview-Driven and Questionnaire - Driven Concept Mapping Processes: A Focus On The Research-Teaching Nexus In Higher Education". Eighth International Conference on Concept Mapping, 2018. 